\title{
Scalloped hammerhead sharks swim on their side with diel shifts in roll magnitude and periodicity
}

\author{
Mark Royer ${ }^{1 *}$, Kelsey Maloney ${ }^{1}$, Carl Meyer ${ }^{1}$, Edward Cardona², Nicholas Payne ${ }^{3}$, Kate Whittingham4, \\ Guilherme Silva ${ }^{5}$, Chloe' Blandino ${ }^{1}$ and Kim Holland ${ }^{1}$
}

\begin{abstract}
Background: Great hammerhead sharks (Sphyrna mokarran) routinely swim on their sides and periodically roll from side to side. A previous study used wind tunnel tests with a rigid model hammerhead shark to demonstrate that the rolling behavior could improve swimming efficiency using the tall first dorsal fin as a lift-generating surface. Scalloped hammerhead sharks (Sphyrna lewini) also have proportionally taller dorsal fins compared to pectoral fins than most shark species and similar to that of great hammerhead sharks, and thus might exhibit similar rolling behavior. This was assessed by deploying multi-sensor accelerometer instrument packages on free-swimming adult scalloped hammerhead sharks to directly measure swimming depth, body orientation and swimming performance. Specific objectives were to (1) determine whether scalloped hammerhead sharks exhibit side swimming and rolling behavior, (2) characterize the patterns of these behaviors, and (3) evaluate the purpose of these behaviors.

Results: We obtained 196.7 total days (4720 h) of data from 9 free-swimming adult scalloped hammerhead sharks equipped with multi-instrument biologgers with deployment durations ranging from 7 to 29 days. All sharks exhibited rolling behavior throughout the entire period of observation. The roll angle magnitude and periodicity of rolling showed a clear diel pattern. During daytime, the sharks spent an average of $48 \%$ of the time swimming at a roll angle $>30^{\circ}$, with an average roll angle of $41^{\circ}$ and rolling periodicity of around $4 \mathrm{~min}$. At night, the sharks spent an average $82 \%$ of their time at an angle $>30^{\circ}$, with an average roll angle of $60^{\circ}$ and rolling periodicity of around 13 min. In addition to an increase in degree of roll and roll duration, overall dynamic body acceleration (ODBA) also increased at night, and tailbeat frequency was more regular and consistent than during daytime.
\end{abstract}

Conclusion: We observed rolling behavior in scalloped hammerhead sharks similar to that observed in great hammerhead sharks. The diel changes in roll angle and periodicity were accompanied by other changes in swimming behavior. These changes are possibly due to interplay between reducing cost of transport and social interactions with conspecifics.

Keywords: Scalloped hammerhead shark, Roll, Accelerometer, Diel variation, Swimming behavior, Tail beat frequency, ODBA, Hydrodynamic adaptations, Hydrodynamic stability, Form and function

*Correspondence: royerm@hawaii.edu

1 Hawai'i Institute of Marine Biology, University of Hawai'i at Mānoa, 46-007 Lilipuna Rd., Kaneohe, HI 96744, USA

Full list of author information is available at the end of the article

\section{Background}

Most shark species swim in an upright posture with lateral body oscillations, utilizing the dorsal fin for lateral stability and pectoral fins for horizontal stability as well as anterior lift generators that counteract the posterior lift generated by the caudal fin [1-4]. A study by Payne 
et al. [5] using multi-sensor accelerometer instrument packages observed great hammerhead sharks (Sphyrna mokarran) spend up to $90 \%$ of their time swimming on their sides at a roll angle of between 50 and $75^{\circ}$. Great hammerhead sharks are unusual among sharks in having a dorsal fin longer than their pectoral fins, and it was hypothesized that they use this tall first dorsal fin as a liftgenerating surface during side swimming, thus increasing the effective span of the lifting surfaces [5]. Hydrodynamic modeling using empirical data from a rigid model of a great hammerhead shark in a wind tunnel demonstrated that this side swimming behavior could reduce drag relative to lift generation, thus reducing the cost of transport (defined as energy expenditure per distance swum) by about $10 \%$ compared to conventional upright swimming [5]. Scalloped hammerhead sharks (Sphyrna lewini) have a similar body plan to great hammerhead sharks, including a tall first dorsal fin that may be longer than their pectoral fins and thus, in theory, could also exhibit side swimming behavior to reduce their transport costs. We deployed multi-sensor accelerometer biologging packages on free-swimming adult scalloped hammerhead sharks to directly measure swimming depth, body orientation and swimming performance. Our objectives were to determine whether scalloped hammerhead sharks exhibit rolling behavior and if so, whether there are any patterns in that behavior and any interplay between rolling behavior and other aspects of swimming performance.

\section{Methods}

Measurement of body orientation and swimming behavior To measure body orientation and swimming behavior in scalloped hammerhead sharks, we used an instrument package consisting of a tri-axial accelerometer tag combined with a depth and temperature archiving tag housed in a syntactic foam float (2000 $\mathrm{m}$ depth rating) equipped with a timed-release mechanism and Argos satellite-linked telemetry tag to facilitate recovery. The tri-axial accelerometer tag was either a TDR10-XB-340 $(56 \times 38 \times 24 \mathrm{~mm} 69$ g; Wildlife Computers., Redmond, WA) or a TDR10-Daily Diary-278 $(74 \times 57 \times 36 \mathrm{~mm}$, 117 g; Wildlife Computers., Redmond, WA). Tri-axial acceleration was sampled at either $16 \mathrm{~Hz}$ or $32 \mathrm{~Hz}$, triaxial magnetometry at $1 \mathrm{~Hz}$, and depth every $5 \mathrm{~s}$ using an MK9 archival tag (Wildlife Computers, Redmond, WA). Each package also contained an SPOT5 or SPOT6 Argos satellite-linked transmitter $(80 \times 20 \times 11 \mathrm{~mm}$, 30 g; Wildlife Computers., Redmond, WA) to indicate the package position when it floated to the surface following release from the tagged animal and a VHF transmitter (MM130B; $16 \mathrm{~mm}$ diameter, $60 \mathrm{~mm}$ length, $20 \mathrm{~g}$; ATS, USA) to facilitate package recovery. Two packages deployed on two separate sharks were equipped with a Little Leonardo video logger $(20 \times 11 \times 52 \mathrm{~mm}, 16 \mathrm{~g}$; Little Leonardo Co., Tokyo, Japan). The video logger on HH11 was duty-cycled to record for $3 \mathrm{~h}$ each day from 5:50 to $8: 50$ on May 21, 22, 23, 24 and an additional 13 min from 5:50 to $6: 03$ on the 25th.

\section{Shark capture and handling}

All sharks were caught using baited hooks on demersal longlines inside Kāne ohe Bay (N 21.45 , W 157.80 $)$ on the island of $\mathrm{O}^{6}$ ahu (Hawai' $\mathrm{i}$, USA). To ensure captured sharks were in good condition, longlines were checked every $30 \mathrm{~min}$ and soak times were kept to less than $2 \mathrm{~h}$. Captured sharks were brought alongside a $5 \mathrm{~m}$ skiff and secured with a rope around the caudal peduncle. A hose connected to an in-water bilge pump was inserted into the mouth to provide constant water flow across the gills while the shark was being measured and instrumented. The tag package was attached by a fusible stainless steel cable tie $(360 \mathrm{~mm}, 8 \mathrm{~g}$; Little Leonardo Co., Tokyo, Japan) passed through two holes drilled through the base of the dorsal fin and secured around the syntactic foam float package. Each package contained a timed-release mechanism with a pre-programmed duration (RT-4, $16 \mathrm{~mm}$ diameter $\times 19 \mathrm{~mm}$ length $10 \mathrm{~g}$; RT-5, $20 \mathrm{~mm}$ diameter $\times 38 \mathrm{~mm}$ length, $20 \mathrm{~g}$; Little Leonardo Co., Tokyo, Japan). Packages were programmed to release after $7(n=2), 21(n=1)$, or $23(n=8)$ days. When the countdown timer reached zero, a fusible capsule severed the stainless steel band allowing the package to detach from the shark and float to the surface. Package recovery was accomplished through initial position estimates from Argos satellite transmissions followed by the use of a handheld directional radio receiver tuned to the Argos and VHF transmitter frequencies to guide a chase boat to the floating package. Contact information was also displayed on the packages in case members of the general public found them.

Fin measurements were collected from two of the tagged sharks (HH10, HH11) and two additional opportunistically sampled individuals of similar size. Fin height refers to the perpendicular distance from the fin baseline to the tip of the fin and fin length refers to the distance from the fin origin to the end of the free rear tip (sensu [6]).

Tagging procedures were approved by the ethics committee at the University of Hawaii (Institutional Animal Care and Use Committee Protocol \#05-053).

\section{Data processing and analysis}

Archived data were downloaded from nine recovered tag packages. All 32- $\mathrm{Hz}$ tri-axial acceleration data were resampled at $16 \mathrm{~Hz}$ to facilitate analyses. Acceleration 
and depth data were analyzed using Igor Pro 8 (WaveMetrics Inc., Portland, OR, USA) with the 'Ethographer' package [7]. A low-pass filter of $0.3 \mathrm{~Hz}$ was used to estimate the static (gravitational) and the dynamic (tail stroking) components of the acceleration signal for each axis. The static acceleration components from the $x, y$, and $z$ axes were used to calculate the roll angles of the shark, where $x$ is the surge axis, $y$ sway axis, and $z$ the heave axis [8]:

$$
\text { Roll }=\arctan \left(y /\left(x^{2}+z^{2}\right)^{1 / 2}\right)(180 / \pi) .
$$

To correct for the attachment angle of the tag to each shark, the roll angle data were corrected to $0^{\circ}$ centered $[9,10]$. The mask function in the Ethographer package was used to separate deployment periods into daytime and nighttime observations based on local sunrise and sunset times (Astronomical Applications Department of the U.S. Naval Observatory [11]).

For the purposes of this analysis, we define rolling periodicity as the time taken to transition from upright (vertical) to one side (to a minimum of $30^{\circ}$ ), back through vertical to the other side at a minimum angle of $30^{\circ}$ and back to vertical. This is analogous to the definition of a tailbeat cycle. We used the following metrics to quantify diel variation in rolling behavior during swimming; (1) percent of time spent at a roll angle greater than $30^{\circ}$, (2) the dominant absolute roll angle, and (3) the roll cycle period. The percent of time spent at a roll angle greater than $30^{\circ}$ was calculated using the mask feature in Ethographer. An additional mask was used to select all roll data where the absolute roll angle exceeded $30^{\circ}$. The duration of the $30^{\circ}$ mask was divided by the total data duration for both the daytime and nighttime. The dominant absolute roll angle was calculated using a probability density histogram plot with $1^{\circ}$ bins, with the peak bin designated as the dominant roll angle. The dominant roll period was calculated using a power spectral density plot of the roll data with the peak as the dominant roll frequency which was subsequently converted to roll period. We used paired $t$ tests to compare the mean rolling behavior characteristics during day versus night. Normality was assessed using histograms of mean differences between day and night for each behavior characteristic.

We evaluated potential diel changes in shark swimming activity by comparing day versus nighttime overall dynamic body acceleration (ODBA) and tailbeat frequencies. Both ODBA and tailbeat frequency have been used as proxies for energy expenditure [12-17]. We calculated ODBA by summing the absolute values of the dynamic acceleration from all three [surge $(x)$, heave $(y)$, sway $(z)]$ axes $[12,13]$. Overall day and night averages for ODBA were calculated for each individual by first calculating average ODBA for each day and night and then calculating the overall average and standard deviation across each repeated measure. Tailbeat frequency was calculated from the dynamic component of $x$-axis (surge) acceleration as this provided the cleanest signal from the three axes. The tailbeat signal was evident in all three axes but the traditionally used sway axis signal was noisier (composite waveform with multiple frequencies) than the surge axis. Tag package wobble and phase differences of between anterior and posterior swaying are possible explanations for the complexity of the dynamic component of the $y$-axis (sway) acceleration signal. The overall dominant tailbeat frequencies for day and night were calculated using the peak in power spectral density plots for each individual. Tailbeat frequency was further analyzed by generating continuous wavelet transformation spectrograms of the swaying acceleration across the entire deployment (no separation of day and night) for each shark. Sharks periodically made multiple (up to 7) steep nocturnal dives to 600-900 m depth with intense swimming activity (high ODBA, tailbeat frequency and amplitude) occurring during these events. We omitted these deep dive events from our analysis to facilitate comparison of dominant (i.e. non-deep diving) daytime and nighttime swimming behavior. Paired $t$ tests were used to test for significant diel differences in mean ODBA and tailbeat frequency. Normality was assessed using histograms of mean differences between day and night for ODBA and tailbeat frequency.

\section{Results}

\section{Instrument deployments and fin measurements}

We deployed biologging packages on 11 adult male scalloped hammerhead sharks ranging in size from $204 \mathrm{~cm}$ to $270 \mathrm{~cm}$ Total Length (TL, Table 1) of which 10 were successfully recovered and 9 recorded accelerometer data. In total, we obtained 196.7 total days $(4720 \mathrm{~h})$ of accelerometer and depth data with individual deployment durations ranging from 7 to 29 days (Table 1). For recovered tag packages, horizontal distance from tagging location to pop-up point ranged from 8.1 to $51.1 \mathrm{~km}$, and all packages surfaced within $5 \mathrm{~km}$ of the coast of $\mathrm{O}^{6} \mathrm{ahu}$. The package timer for HH11 was set for 7 days but it stayed on the animal for 29 days, possibly due to damage sustained to the wires connecting the stainless belt and release timer. The package for $\mathrm{HH} 3$ was programmed for 21 days but was knocked off prematurely 14 days into the deployment. The package from HH11 failed to transmit any satellite or VHF positions due to damaged sustained during deployment but was discovered $248 \mathrm{~km}$ away from 
Table 1 Details of accelerometer tag package deployments on nine adult male scalloped hammerhead sharks

\begin{tabular}{|c|c|c|c|c|c|c|c|c|}
\hline Shark ID & Tagging date & Sex & Tagging latitude (DD) & Tagging longitude (DD) & $\mathrm{PCL}(\mathrm{cm})$ & $\mathrm{TL}(\mathrm{cm})$ & Accel. tag type & $\begin{array}{l}\text { Total deployment } \\
\text { data time (days } \\
\text { hh:mm) }\end{array}$ \\
\hline $\mathrm{HH} 1$ & $5 / 26 / 16$ & Male & 21.45238 & -157.79405 & - & $\sim 260^{a}$ & $\mathrm{DD}$ & $0603: 13$ \\
\hline $\mathrm{HH} 3$ & 7/13/16 & Male & 21.43401 & -157.78619 & 161 & 221 & $\mathrm{DD}$ & $1816: 24$ \\
\hline $\mathrm{HH} 5$ & $5 / 25 / 17$ & Male & 21.45212 & -157.7915 & 166 & 240 & $\mathrm{DD}$ & $2222: 17$ \\
\hline $\mathrm{HH} 6$ & $6 / 5 / 17$ & Male & 21.48026 & -157.83043 & 164 & 240 & $\mathrm{DD}$ & $2205: 36$ \\
\hline $\mathrm{HH} 7$ & $6 / 26 / 17$ & Male & 21.48405 & -157.82669 & 187 & 270 & TDR10 & 22 20:47 \\
\hline $\mathrm{HH} 8$ & $6 / 27 / 17$ & Male & 21.481373 & -157.829282 & 136 & 204 & TDR10 & $2215: 38$ \\
\hline $\mathrm{HH} 9$ & $7 / 18 / 17$ & Male & 21.483062 & -157.82776 & 165 & 245 & $\mathrm{DD}$ & $1604: 40$ \\
\hline $\mathrm{HH} 10$ & $7 / 26 / 17$ & Male & 21.482761 & -157.827998 & 181 & 263 & TDR10 & 22 05:00 \\
\hline $\mathrm{HH} 11$ & $5 / 17 / 18$ & Male & 21.482323 & -157.828314 & 179 & 256 & $\mathrm{DD}$ & 29 04:50 \\
\hline
\end{tabular}

a rough estimate of total body length was taken when the shark was along the side of the boat

the tagging location on the shore of the island of $\mathrm{Ni}$ ' ihau approximately 320 days after the expected pop-up time. We measured the fin sizes of four adult male scalloped hammerhead sharks (two of which were tagged), and all four had dorsal fin heights exceeding pectoral fin heights (Table 2), and indeed larger dorsal to pectoral fin height ratios (1.17:1 average) than great hammerhead sharks [5] $(1.07: 1$,$) .$

\section{Rolling behavior}

All sharks exhibited rolling behavior throughout the entire observation period. We found significant diel variation in the duration, magnitude and periodicity of scalloped hammerhead shark rolling behavior. Diel differences were characterized by more extreme roll angles, more time spent side swimming, and longer side swimming bouts during night than day (Figs. 1, 2). Nighttime rolling behavior was more consistent whereas daytime rolling behavior was interspersed with varying periods (several minutes to several hours) of upright swimming. The mean proportion of time spent swimming at a $>30^{\circ}$ roll angle increased from $48.1 \%$ ( $\pm 16.1 \%$ SD) during daytime to $82 \%( \pm 4.7 \%$ SD) at night (Table 3). During daytime, three sharks spent less than half of their time side swimming (HH8 40.8\%; HH9 13.7\%; HH11 35.3\%), whereas at night no shark spent less than $74.3 \%$ of the time side swimming at $\mathrm{a}>30^{\circ}$ roll angle (Fig. 2, Table 3 ). All nine sharks had a significantly greater mean dominant roll angles at night (average $60.2^{\circ}, \pm 3.5 \mathrm{SD}$ ) than during the day (average $40.72^{\circ}, \pm 16 \mathrm{SD}$ ) (paired $t$ test, $t=-3.39$, $d f=8, p=0.0095)$. The dominant daytime absolute roll angles ranged from 0.5 to $53.5^{\circ}$. Only one individual (HH9) had a dominant daytime roll angle $<30^{\circ}$. The dominant nighttime absolute roll angles ranged from 55.5 to $66.5^{\circ}$ (Table 3). All sharks except HH3 exhibited a longer dominant roll periodicities at night (average $12.2 \mathrm{~min}, \pm 9.5 \mathrm{SD}$ ) than during daytime (average $8.8 \mathrm{~min}, \pm 13.9 \mathrm{SD}$ ). HH3 was the only individual observed exclusively in the shallow $(<15 \mathrm{~m})$ confines of Kāne'ohe Bay (based on the depth data and tag pop-up location). No significant diel differences in mean dominant roll periodicity (paired $t$ test, $t=-0.55, d f=8, p=0.5955)$ were evident with $\mathrm{HH} 3$ in the analysis. However, with HH3 excluded from analysis, mean dominant roll periodicity was significantly greater during night (average $=13.1 \mathrm{~min} \pm 9.7$ ) than day (average $=4.3 \mathrm{~min} \pm 1.9 \mathrm{SD}$ ), (paired $t$ test, $t=-3.14, d f=7, p=0.0164$ ). Side swimming and rolling behavior occurred both while sharks were descending and ascending through the water column and also while swimming at constant depth. All sharks in this study demonstrated a transition between their daytime and nighttime rolling behaviors (Fig. 3) at sunrise and sunset each day.

\section{Swimming performance}

Each shark exhibited a diel change in swimming performance, with faster and more consistent tailbeat activity as well as significantly higher ODBA values at night. Grand mean ODBA ranged from $1 \pm 0.25 \mathrm{~m} / \mathrm{s}^{2}$ at night to $0.82 \pm 0.20 \mathrm{~m} / \mathrm{s}^{2}$ during the day $(t=-6.456, p=0.0002)$. Mean tail beat frequency was significantly slower and more variable during the day than at night (paired $t$ test, $t=2.71, d f=8, p=0.026)$. Spectral analysis showed an increase in the tailbeat frequency and consistency at night (Fig. 4). The weak (low amplitude) signal during the daytime showed less consistent periods of tailbeat activity and occasional gliding behavior (Fig. 4, Additional files $1,2,3,4)$. 


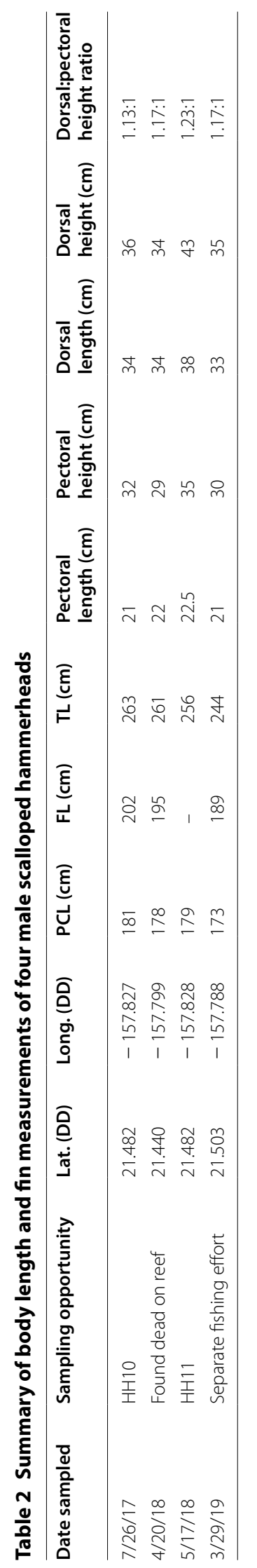




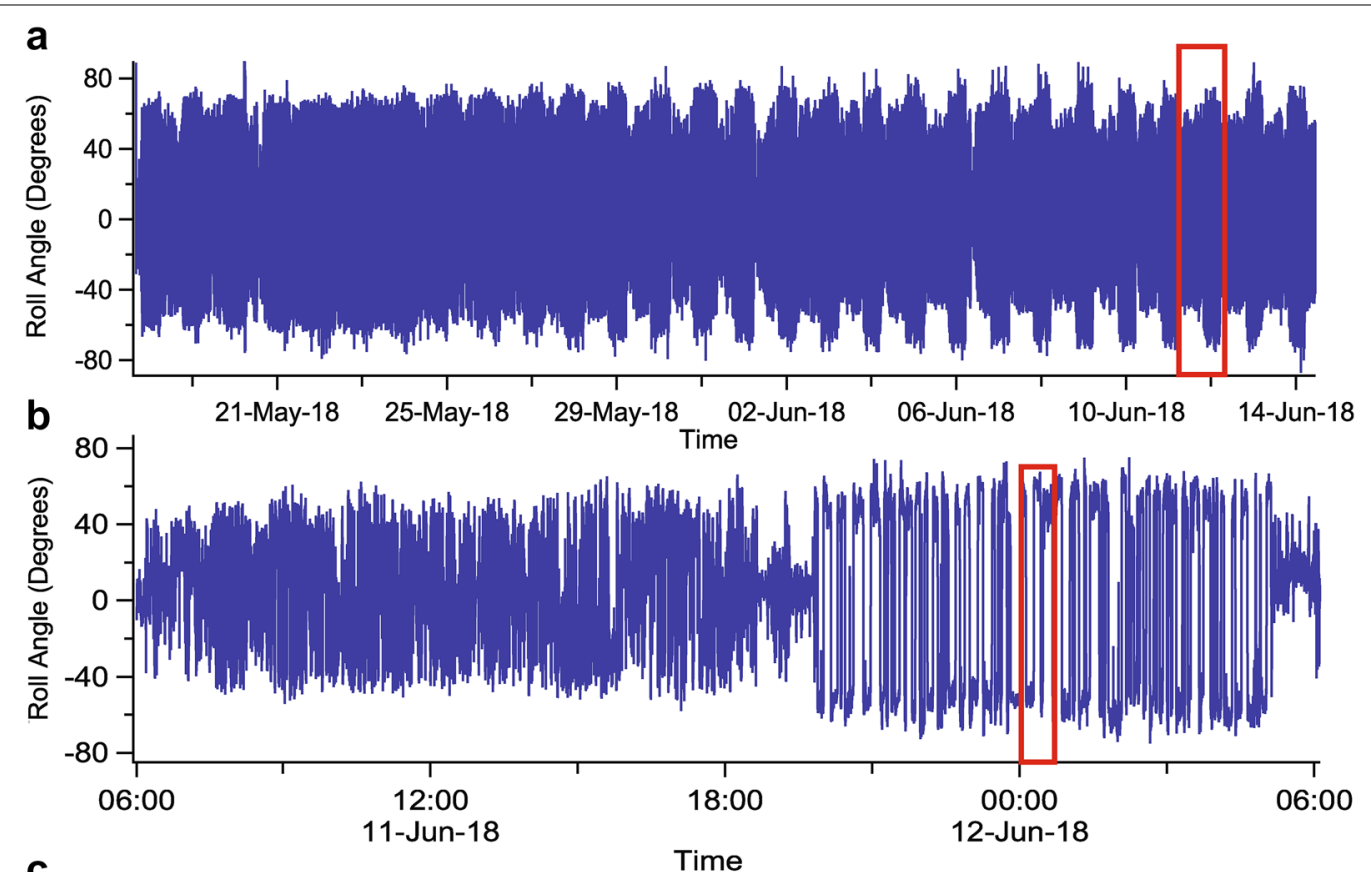

C

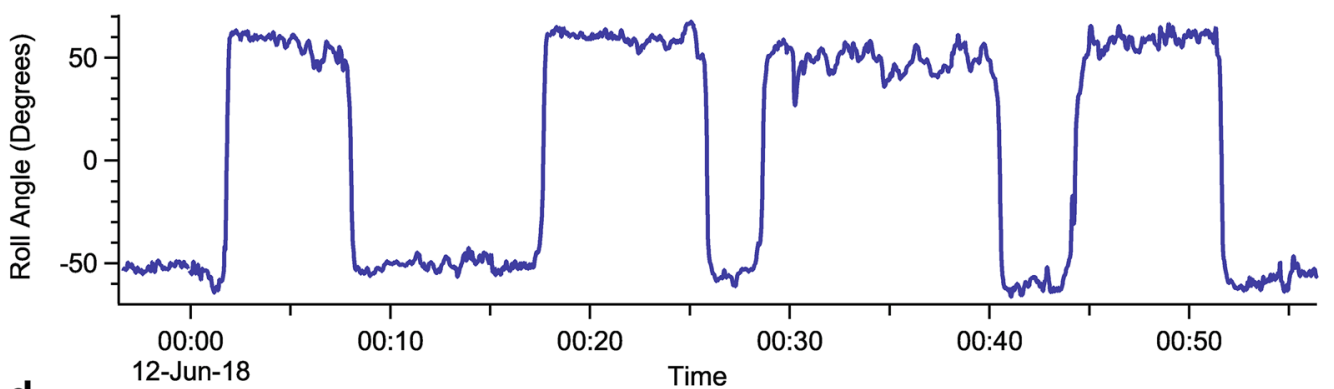

d
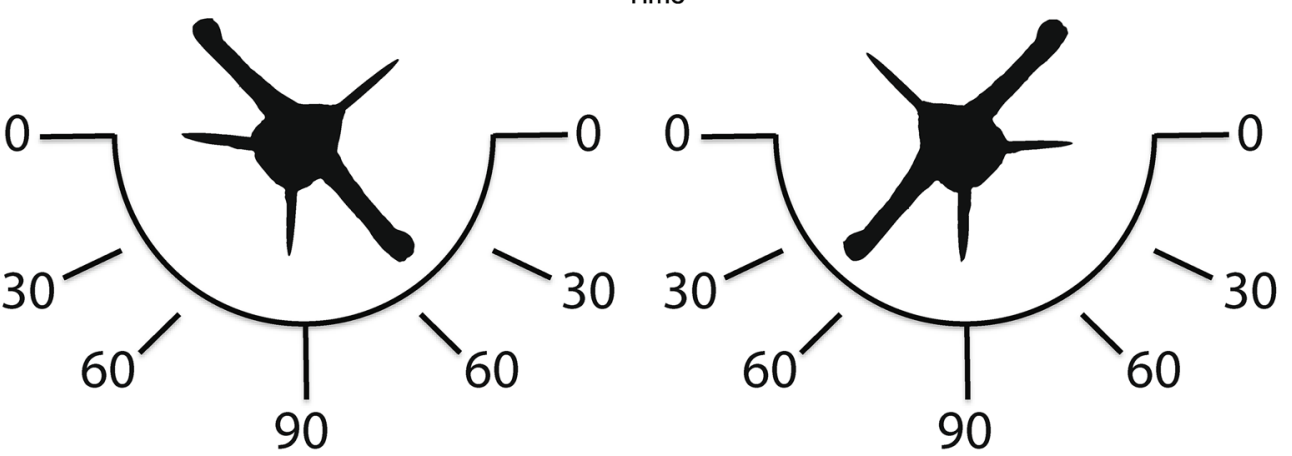

Fig. 1 The rolling behavior of a scalloped hammerhead shark. a Time series data of the roll angle of $\mathrm{HH} 11$ for the entire 29-day deployment period. A diel pattern is seen, with increased magnitude in the roll angle each night. Red box indicates the time segment in $\mathbf{b}$. A 24-h segment of the time series in a shows the increase in the roll period at night with longer durations spent on each side. Red box indicates the time segment in $\mathbf{c}$. An hour-long segment at night shows the shark swimming at approximately a $60^{\circ}$ angle with negative readings indicating banking to the left side and positive readings indicating banking to the right side. $\mathbf{d}$ The silhouettes of a forward facing scalloped hammerhead banked at $60^{\circ}$ angles to the left and right show how the dorsal fin can be used as a lift-generating surface, forming a dihedral angle with the pectoral fin

\section{Video logger}

Daytime video footage showed HH11 swimming in a tortuous pattern in the water column and near the seafloor at depths between 50 and $100 \mathrm{~m}$. Video from May 22 thru
25 showed the HH11 associating with two other adult male scalloped hammerhead sharks that could be seen side swimming and turning frequently throughout the footage (see Additional files 3, 4, 5). 


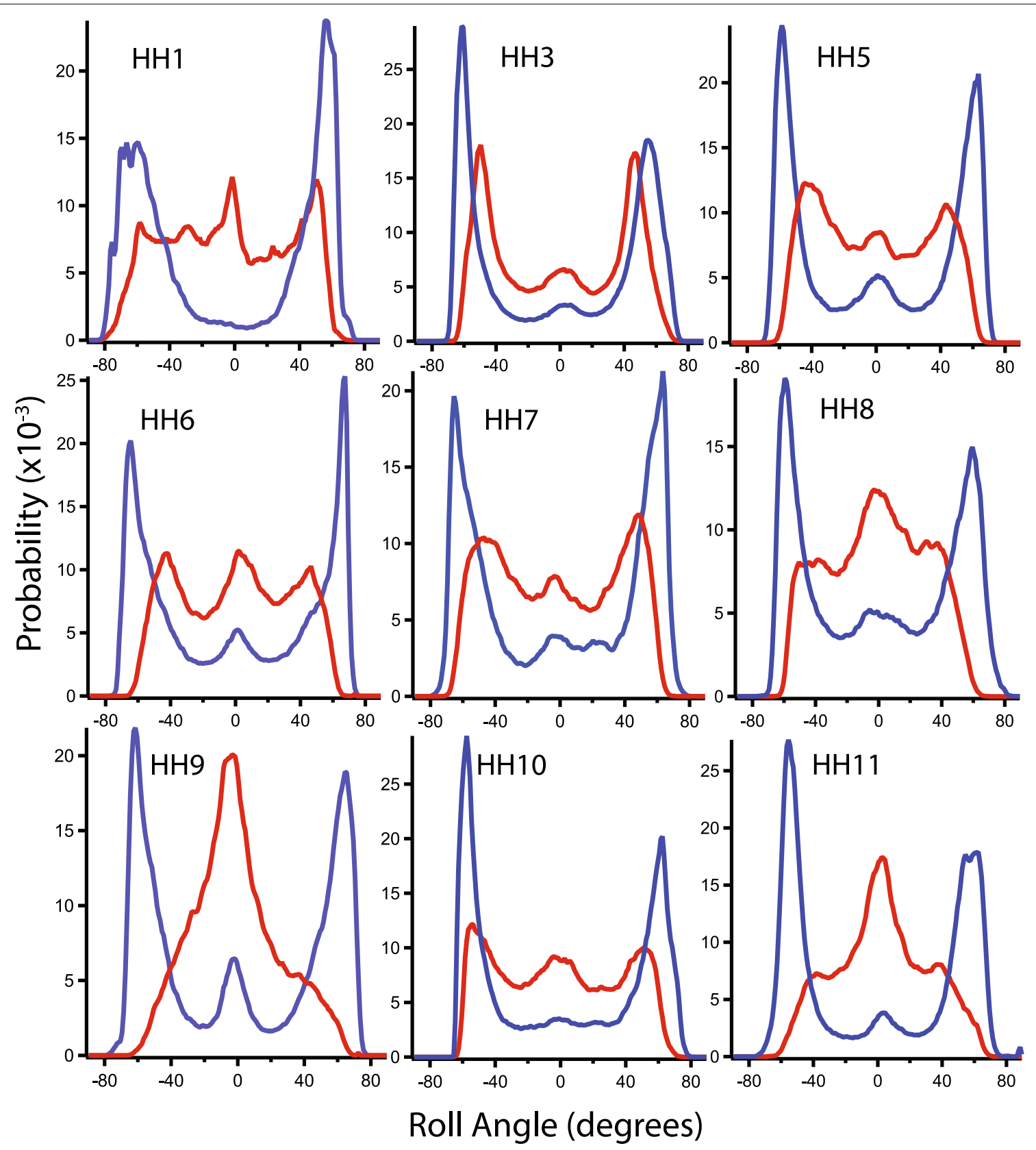

Fig. 2 Roll angle probability for day and night all sharks. Roll angle probability distribution histograms for each shark for their entire deployments. Blue indicates the nighttime and red indicates the daytime roll angle probability. Differences in the daytime roll angle probability varies between sharks

\section{Discussion}

As predicted by the overall similarity in body plan of the two hammerhead species (i.e. long first dorsal fins compared to pectoral fins and laterally compressed bodies), we found that scalloped hammerhead sharks, like great hammerhead sharks, spend a majority of their time swimming on their side [5]. We predict that other hammerhead shark species with high dorsal to pectoral fin ratios and laterally compressed bodies (which can act as lift-generating surfaces) will also exhibit this behavior whereas side swimming behaviors are probably absent from smaller hammerhead shark species which lack high dorsal:pectoral fin ratios [18]. Measurements of the dorsal and pectoral fins from four adult scalloped hammerhead sharks captured during this study (two of which were tagged) revealed a dorsal fin to pectoral 
Table 3 Summary of daytime and nighttime rolling behavior and swimming activity

\begin{tabular}{|c|c|c|c|c|c|c|c|c|c|c|}
\hline \multirow[t]{2}{*}{ Shark ID } & \multicolumn{2}{|c|}{$\begin{array}{l}\text { Percent duration roll } \\
\text { angle }>30^{\circ}\end{array}$} & \multicolumn{2}{|c|}{$\begin{array}{l}\text { Dominant absolute } \\
\text { roll angle }\left(^{\circ}\right)\end{array}$} & \multicolumn{2}{|c|}{$\begin{array}{l}\text { Dominant roll period } \\
\text { (s) }\end{array}$} & \multicolumn{2}{|c|}{ Average ODBA $\pm S D\left(m / s^{2}\right)$} & \multicolumn{2}{|c|}{$\begin{array}{l}\text { Dominant } \\
\text { tailbeat period (s) }\end{array}$} \\
\hline & Day & Night & Day & Night & Day & Night & Day & Night & Day & Night \\
\hline $\mathrm{HH} 1$ & 54.3 & 91.2 & 51.5 & 56.5 & 512 & 2048 & $0.47( \pm 0.03)$ & $0.56( \pm 0.03)$ & 2.34 & 2.28 \\
\hline $\mathrm{HH} 3$ & 68.0 & 84.5 & 48.5 & 60.5 & 2731 & 293 & $0.86( \pm 0.09)$ & $0.96( \pm 0.05)$ & 2.08 & 2.07 \\
\hline $\mathrm{HH} 5$ & 54.4 & 79.6 & 43.5 & 59.5 & 228 & 341 & $0.95( \pm 0.05)$ & $1.14( \pm 0.06)$ & 2.14 & 2.15 \\
\hline $\mathrm{HH} 6$ & 50.6 & 79.8 & 44.5 & 66.5 & 205 & 512 & $0.85( \pm 0.06)$ & $0.96( \pm 0.04)$ & 2.03 & 2.04 \\
\hline $\mathrm{HH7}$ & 59.8 & 81.2 & 48.5 & 63.5 & 210 & 1048 & $0.90( \pm 0.06)$ & $1.12( \pm 0.03)$ & 2.31 & 2.29 \\
\hline $\mathrm{HH} 8$ & 40.8 & 74.3 & 37.5 & 59.5 & 171 & 341 & $0.89( \pm 0.10)$ & $1.13( \pm 0.05)$ & 2.03 & 1.98 \\
\hline $\mathrm{HH} 9$ & 13.7 & 82.2 & 0.5 & 62.5 & 171 & 455 & $0.50( \pm 0.08)$ & $0.64( \pm 0.02)$ & 2.31 & 2.18 \\
\hline $\mathrm{HH} 10$ & 55.8 & 81.8 & 53.5 & 57.5 & 205 & 512 & $0.99( \pm 0.10)$ & $1.16( \pm 0.04)$ & 2.38 & 2.21 \\
\hline $\mathrm{HH} 11$ & 35.3 & 86.0 & 38.5 & 55.5 & 341 & 1024 & $0.98( \pm 0.12)$ & $1.33( \pm 0.15)$ & 2.34 & 2.24 \\
\hline
\end{tabular}

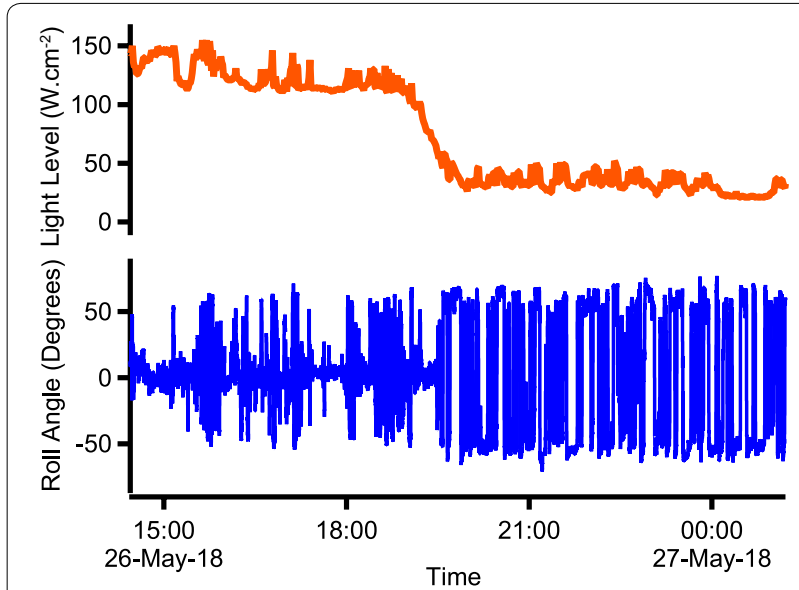

Fig. 3 Transition from daytime to nighttime rolling behavior at sunset. HH11 transitions from day to night rolling behavior as light level decreases during sunset from 19:20 to 20:00, with an increase in the roll angle and roll period

fin height ratio (1.17:1 average) exceeding those seen in great hammerhead sharks (1.07:1). This is in contrast to previous findings from Clark and Von Schmidt [19] where fin measurements were inferred from a taxonomic key that referenced the range of body lengths of adults and had the heights of the dorsal fins expressed as a percentage of body length. It is possible Clark and Von Schmidt [19] combined morphometric measurements from juvenile and adult individuals and consequently obscured the high dorsal fin ratio characteristic of adult scalloped hammerhead sharks. No observations of rolling behavior have been reported for juvenile scalloped hammerhead sharks but ontogenetic changes in characteristics such as buoyancy and fin aspect ratios may gradually shift their hydrodynamic characteristics until this behavior emerges [20, 21]. Identifying the ontogenetic onset of side swimming will help to more clearly understand how this behavior is adaptive for hammerhead sharks.

We found clear diel rhythms in the swimming posture and gait of adult scalloped hammerheads sharks with more side swimming, greater roll angles, higher activity and more consistent tail beating at night than during the day. Diel changes in swimming behavior may reflect shifts between daytime social interactions [22-24] and nocturnal traveling, with the later consisting of more directional swimming. Scalloped hammerhead sharks are known to form large daytime aggregations at fixed locations and then disperse over a more extensive area at night (e.g. [22-24]). Maintaining school cohesion and social interactions at a fixed location during daytime may require more tortuous swimming, modulation of rolling behaviors and periods of passive gliding. These daytime behaviors were observed in footage from the video logger on HH11, when it was swimming with a group of conspecifics on 4 consecutive days (Fig. 5, Additional files 1, 2, $3,4,5)$.

Similarities in side swimming behavior and morphology between great hammerhead [5] and scalloped hammerhead sharks [this study] provide interesting insight into the evolution of novel morphological traits and behavior of large hammerheads. The side swimming behavior exhibited in large hammerhead sharks is probably a "recent" locomotor strategy enabled by the derived body plan (including fin size and placement) of these divergent species $[5,25]$. The ability to maximize locomotor efficiency during sustained swimming and prey capture is crucial for managing energy budgets and exerts strong selective pressure [26, 27]. It is likely that the reconfiguration of the fins during locomotion allows for large hammerheads to utilize their morphology for maneuvering events and for efficient directional 


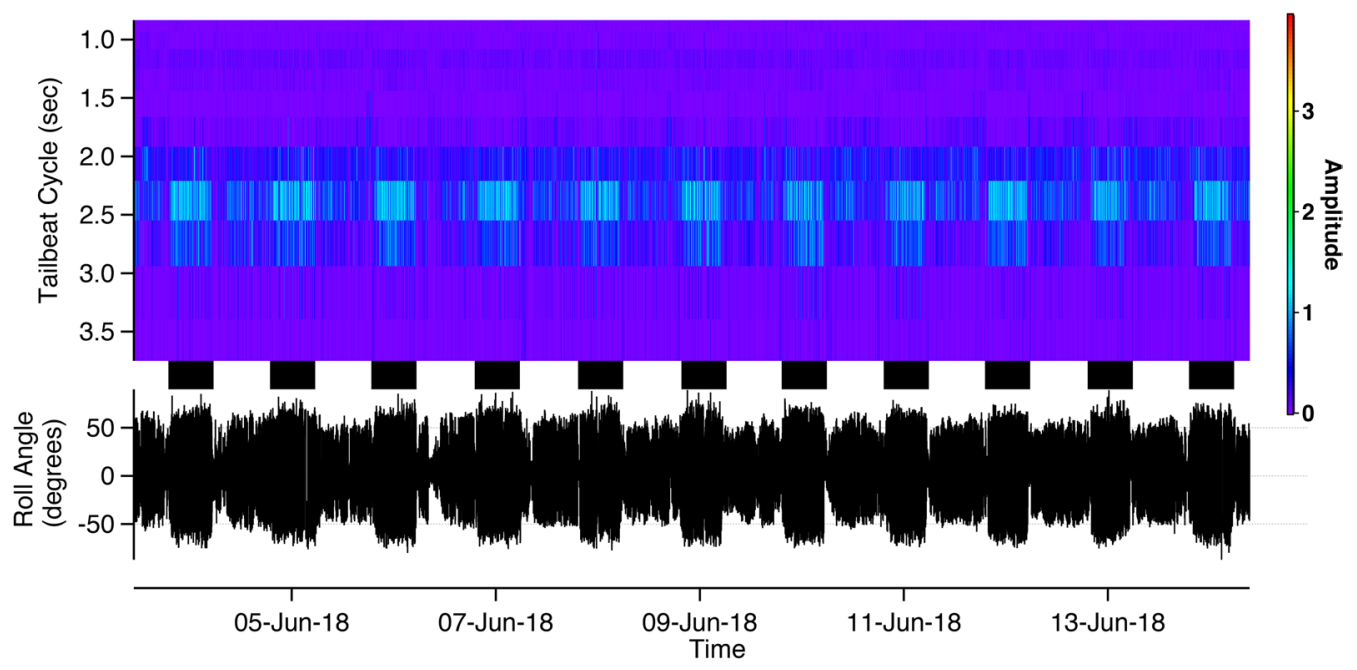

Fig. 4 Diel variation in swimming performance and roll behavior. A wavelet spectrogram of the heaving acceleration for 9 night-day cycles from $\mathrm{HH} 1$ 1. Warmer colours in the spectrogram represent stronger signals, whereas cooler colours represent weaker signals. The signal is weaker during each daytime period, indicating a less consistent tailbeat and frequent gliding behavior associated with the changes in the rolling behavior

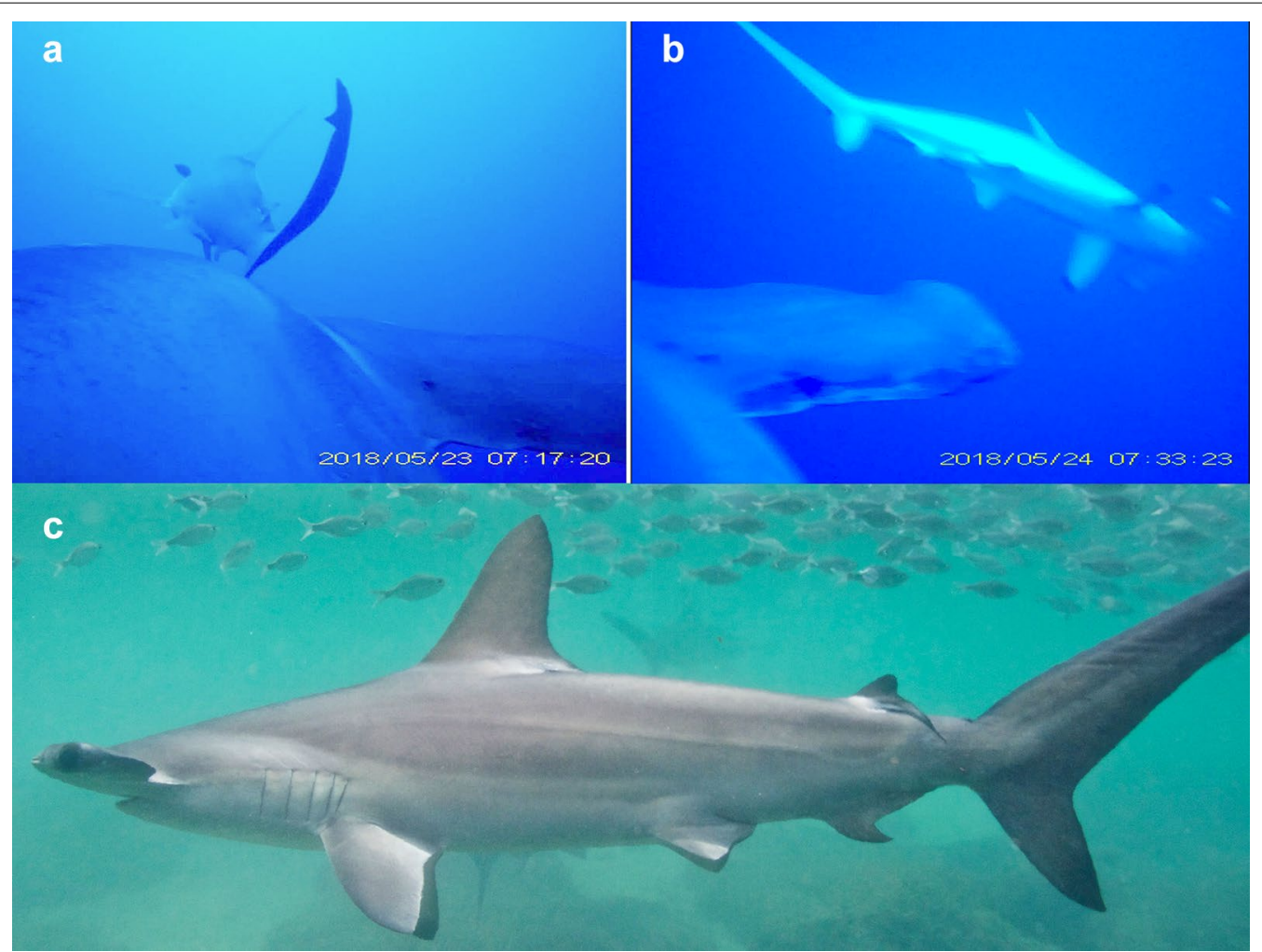

Fig. 5 Footage showing fin position of rolled and upright scalloped hammerhead sharks. The camera footage on HH11 had two additional male scalloped hammerheads swimming with the tagged animal for several days. Rolling behavior can be seen of the camera-tagged shark (relative to a horizontal surface of the seafloor) as well as the two additional scalloped hammerheads in the footage $(\mathbf{a}, \mathbf{b})$. The dihedral angle of the lift surfaces (dorsal and high pectoral fin) can be seen on the sharks swimming on their side $(\mathbf{a}, \mathbf{b})$, compared to the anhedral angle of the pectoral fins when a scalloped hammerhead swims upright (c) 
swimming. Both species are noted for their maneuverability, making rapid tight turns when chasing and subduing prey $[18,28-31]$. In their upright posture, they can maximize their maneuverability potential, conducting rapid tight turns while keeping their body level, due to their lateral flexure, head shape, anhedral pectoral fin positioning, and large dorsal fin [2, 18, 28] (Fig. 5). Both species are also known to conduct long-distance migrations [32-36]. These species, when cruising, swim at a rolled angle, utilizing the dorsal fin and high pectoral fin as lift-generating surfaces and thus increase their effective lift span compared to normal upright swimming. Scalloped hammerhead sharks exhibited nighttime roll angles within the range (between $50^{\circ}$ and $70^{\circ}$ ) of those predicted to provide the lowest cost of transport for great hammerhead sharks [5] (Table 3, Figs. 1, 2, 3). Given the similar body plans of these two hammerhead shark species, both may be reducing cost of transport by side swimming. This hypothesis could be tested through hydrodynamic modeling using wind tunnel tests on a morphologically accurate model of a scalloped hammerhead shark, such as those conducted by Payne et al. [5]. Other hydrostatic and hydrodynamic properties of the body configuration during side swimming that could be examined include shifts in the center of gravity [21,27], shifts in the dihedral of control surfaces [37, 38], and phase relationships of body undulations and control surfaces [27]. Future studies using accelerometer biologgers on other large hammerhead shark species (e.g. smooth hammerhead shark (Sphyrna zygena), Carolina hammerhead shark (Sphyrna gilberti) [39]) will reveal whether side swimming behavior is ubiquitous among all large hammerhead shark species.

\section{Conclusion}

Like great hammerhead sharks, scalloped hammerhead sharks swim at a rolled angle. The deployments of highresolution accelerometer tags on 9 adult male scalloped hammerhead sharks for 7 to 29 days revealed distinct diel variation in rolling behavior and swimming performance. At night, the sharks spend a higher proportion of their time side swimming, with longer bouts on each side and more extreme roll angles. Scalloped hammerhead sharks are also more active and swim more steadily during night than day. Swimming behaviors at night are likely driven primarily by reducing cost of transport during steady swimming whereas daytime behavior is likely a compromise between reducing cost of transport and other factors such as social interactions between conspecifics. The suite of changes in posture and swimming performance that occur on a diel basis support the concept that side swimming enhances swimming efficiency by generating lift from the dorsal fin. These phenomena are underpinned by the form and function of the recent derived body plan of large hammerhead sharks.

\section{Supplementary information}

Supplementary information accompanies this paper at https://doi. org/10.1186/s40317-020-00196-x.

Additional file 1. Scalloped hammerhead gliding behavior. Video footage from $\mathrm{HH} 11$ showing gliding behavior.

Additional file 2. Scalloped hammerhead shark rolling behavior spectrogram. A wavelet spectrogram of the heaving ( $x$-axis) acceleration (center) with the raw dynamic acceleration (top) and the roll angle as an appendix (bottom). The gliding behavior from the video (Additional file 1) can been seen where the tailbeat frequency signal declines while the shark is upright (from 6:46:15 to 6:46:45).

Additional file 3. Scalloped hammerhead shark rolling behavior. Video footage from the camera logger on $\mathrm{HH} 11$ showing rolling behavior of a conspecific.

Additional file 4. Scalloped hammerhead shark rolling behavior with two conspecifics. Video footage from the camera logger on $\mathrm{HH} 11$ showing rolling behavior with two other conspecifics.

Additional file 5. Scalloped hammerhead shark social interaction. Video footage from the camera logger on $\mathrm{HH} 11$ showing social interactions with two other conspecifics and tortuous swimming along the seafloor around $110 \mathrm{~m}$ depth.

\section{Abbreviations}

ODBA: Overall dynamic body acceleration; PCL: Pre-caudal length; FL: Fork length; TL: Total length; Accel.: Accelerometer; DD: Daily Diary (TDR10-Daily Diary-278, Wildlife Computers., Redmond, WA); TDR10:TDR10-XB-340 (Wildlife Computers., Redmond, WA); VHF: Very high frequency.

\section{Acknowledgements}

We would like to thank Kailey Carlson, Karla Haiat, Nathan Hu, Brittany Rackliffe, Julie Lazor, Paige Mino, Tamrynn Clegg, Meghan Maxwell, and Samantha Rucker for assisting with the shark tagging and tag recovery, and to Jeff Muir for providing crucial boat support for tag recovery. We would also like to thank Leiana Robinson, the Robinson Family and the people of $\mathrm{Ni}^{6}$ ihau for finding the $\mathrm{HH} 11$ tag and for Jan Tenbruggencate for coordinating communication and shipping of the recovered tag to us.

\section{Authors' contributions}

MR designed the study. MR planned construction and assembly of biologging packages. MR, KM, EC, KW, CB, and GS constructed and tested biologging packages. MR lead field work operations and attached biologging packages to all sharks. KM, EC, KW, CB, and GS assisted in fieldwork operations including fishing efforts, tagging, and package recovery. CM and NP provided detailed instruction for analyzing accelerometry data. MR, KM, EC, and KW analyzed telemetry data and conducted statistical analyses. MR, KM, and GS analyzed the video footage. MR drafted the main body of the manuscript and $\mathrm{CM}, \mathrm{KH}$, and NP provided significant contributions to written material and revisions. $\mathrm{KM}, \mathrm{CB}$, and GS assisted with manuscript formatting, figure preparation and video editing. MR, CM, and $\mathrm{KH}$ secured funding. All authors read and approved the final manuscript.

\section{Funding}

Funding for this research was provided by the Jessie D. Kay Memorial Research Grant through University of Hawai'i Mānoa Department of Biology, the Hawai' ${ }^{\prime}$ Institute of Marine Biology Lord Endowed Scholarship, the Robinson Family Ocean Studies Assistantship, and PaclOOS.

\section{Availability of data and materials}

The dataset used and analyzed for this study is available from the corresponding author upon reasonable request. 


\section{Ethics approval and consent to participate}

Scalloped hammerhead shark handling and tagging procedures were approved by the ethics committee at the University of Hawaii (Institutional Animal Care and Use Committee Protocol \#05-053)

\section{Consent for publication}

Not applicable.

\section{Competing interests}

Author KNH serves as co-editor-in-chief for this journal. Otherwise, the authors declare that there are no other competing interests.

\section{Author details}

${ }^{1}$ Hawai'i Institute of Marine Biology, University of Hawai'i at Mānoa, 46-007 Lilipuna Rd., Kaneohe, HI 96744, USA. ${ }^{2}$ School of Ocean Science, Bangor University, Menai Bridge, Anglesey LL59 5AB, UK. ${ }^{3}$ Trinity College Dublin, College Green, Dublin 2, Ireland. ${ }^{4}$ Whitman College, 345 Boyer Ave, Walla Walla, WA 99362, USA. ${ }^{5}$ Federal University of São Paulo, Santos 11070-102, Brazil.

\section{Received: 9 October 2019 Accepted: 26 February 2020}

Published online: 19 March 2020

\section{References}

1. Alexander RM. The lift produced by the heterocercal tails of Selachii. J Exp Biol. 1965:43:131-8.

2. Nakaya K. Hydrodynamic function of the head in the hammerhead sharks (Elasmobranchii: Sphyrnidae). Copeia. 1995;1995:330-6.

3. Wilga CD, Lauder GV. Three-dimensional kinematics and wake structure of the pectoral fins during locomotion in leopard sharks Triakis semifasciata. J Exp Biol. 2000;203(Pt 15):2261-78

4. Wilga CD, Lauder GV. Hydrodynamic function of the shark's tail. Nature. 2004;430(7002):850. https://doi.org/10.1038/430850a.

5. Payne NL, losilevskii G, Barnett A, Fischer C, Graham RT, Gleiss AC, Watanabe YY. Great hammerhead sharks swim on their side to reduce transport costs Great hammerhead sharks swim on their side to reduce transport costs. Nat Commun. 2016;7:1-5.

6. Marshall LJ, Barone M. Sharkfin Guide, identifying sharks from their fins. Rome: FAO; 2016

7. Sakamoto KQ, Sato K, Ishizuka M, Watanuki Y, Takahashi A, Daunt F, Wanless S. Can ethograms be automatically generated using body acceleration data from free-ranging birds? PLOS ONE. 2009. https://doi. org/10.1371/journal.pone.0005379.

8. Collins PM, Green JA, Warwick-Evans V, Dodd S, Shaw PJA, Arnould JPY, Halsey LG. Interpreting behaviors from accelerometry: a method combining simplicity and objectivity. Ecol Evol. 2015;5(20):4642-54. https://doi. org/10.1002/ece3.1660.

9. Andrzejaczek S, Gleiss AC, Lear KO, Pattiaratchi CB, Chapple TK, Meekan MG. Biologging tags reveal links between fine-scale horizontal and vertical movement behaviors in tiger sharks (Galeocerdo cuvier). Front Mar Sci. 2019;6:1-13.

10. Kawatsu S, Sato K, Watanabe Y, Hyodo S, Breves JP, Fox BK, et al. A new method to calibrate attachment angles of data loggers in swimming sharks. EURASIP J Adv Signal Process. 2010. https://doi. org/10.1155/2010/732586

11. Astronomical Applications Department of the U.S. Naval Observatory. http://aa.usno.navy.mil/. Accessed 22 Apr 2018, 05 June 2019.

12. Gleiss AC, Wilson RP, Shepard ELC. Making overall dynamic body acceleration work : on the theory of acceleration as a proxy for energy expenditure. Methods Ecol Evol. 2011;2:23-33. https://doi.org/10.1111/j.2041210x.2010.00057x.

13. Qasem L, Cardew A, Wilson A, Griffiths I, Halsey LG, Shepard ELC, et al. Tri-axial dynamic acceleration as a proxy for animal energy expenditure; should we be summing values or calculating the vector? PLOS ONE. 2012:2:23. https://doi.org/10.1371/journal.pone.0031187

14. Lowe CG. Metabolic rates of juvenile scalloped hammerhead sharks (Sphyrna lewini). Mar Biol. 2001;139:447-53. https://doi.org/10.1007/s0022 70100585.

15. Whitney NM, Papastamatiou YP, Holland KN, Lowe CG. Use of an acceleration data logger to measure diel activity patterns in captive whitetip reef sharks, Triaenodon obesus. Aquat Living Resour. 2007. https://doi. org/10.1051/alr.2008006.

16. Gleiss AC, Dale JJ, Holland KN, Wilson RP. Accelerating estimates of activity-specific metabolic rate in fishes: testing the applicability of acceleration data-loggers. J Exp Mar Biol Ecol. 2010;385(1-2):85-91. https://doi. org/10.1016/j.jembe.2010.01.012.

17. Watanabe YY, Lydersen C, Fisk AT, Kovacs KM. The slowest fish: swim speed and tail-beat frequency of Greenland sharks. J Exp Mar Biol Ecol. 2012:426-427:5-11. https://doi.org/10.1016/j.jembe.2012.04.021.

18. Kajiura SM, Forni JB, Summers AP. Maneuvering in juvenile carcharhinid and sphyrnid sharks: the role of the hammerhead shark cephalofoil. Zoology. 2003;106(1):19-28. https://doi.org/10.1078/0944-2006-00086.

19. Clark E, Von Schmidt K. Sharks of the central Gulf coast of Florida. Bull Mar Sci. 1965;15:13-83. https://doi.org/10.1103/physreva.90.040502.

20. Iosilevskii G, Papastamatiou YP. Relations between morphology, buoyancy and energetics of requiem sharks. R Soc Open Sci. 2016. https://doi. org/10.1098/rsos.160406.

21. Gleiss AC, Potvin J, Goldbogen JA. Physical trade-offs shape the evolution of buoyancy control in sharks. Proc R Soc B Biol Sci. 2017. https://doi. org/10.1098/rspb.2017.1345.

22. Klimley AP, Nelson DR. Diel movement patterns of the scalloped hammerhead shark (Sphyrna lewini) in relation to E1 Bajo Espiritu Santo: a refuging central-position social system. Behav Ecol Sociobiol. 1984;15:45-54.

23. Klimley AP. Schooling in the large predator, Sphyrna lewini, a species with low risk of predation: a non-egalitarian state. Zeitschrift für Tierpsychologie. 1985;70:297-319.

24. Klimley AP, Butler SB, Nelson DR, Stull AT. Diel movements of scalloped hammerhead sharks, Sphyrna lewini Griffith and Smith, to and from a seamount in the Gulf of California. J Fish Biol. 1988;33:751-61.

25. Lim DD, Motta P, Mara KR, Martin AP. Phylogeny of hammerhead sharks (family Sphyrnidae) inferred from mitochondrial and nuclear genes. Mol Phylogenet Evol. 2010;55:572-9. https://doi.org/10.1016/j.ympev 2010.01.037.

26. Weihs $D$. Stability versus maneuverability in aquatic locomotion. Integr Comp Biol. 2002;42(1):127-34

27. Fish FE. Balancing requirements for stability and maneuverability in cetaceans. Integr Comp Biol. 2002;42(1):85-93. https://doi.org/10.1093/ icb/42.1.85.

28. Kajiura SM, Holland KN. Electroreception in juvenile scalloped hammerhead and sandbar sharks. J Exp Biol. 2002;205(Pt 23):3609-21.

29. McComb DM, Tricas TC, Kajiura SM. Enhanced visual fields in hammerhead sharks. J Exp Biol. 2009;212(24):4010-8. https://doi.org/10.1242/ jeb.032615.

30. Hoffmann SL, Warren SM, Porter ME. Regional variation in undulatory kinematics of two hammerhead species: the bonnethead (Sphyrna tiburo) and the scalloped hammerhead (Sphyrna lewini). J Exp Biol. 2017;220(18):3336-43. https://doi.org/10.1242/jeb.157941.

31. Strong WR, Snelson FF, Gruber SH. Hammerhead shark predation on stingrays - an observation of prey handling by Sphyrna mokarran. Copeia. 1990;3:836-40.

32. Jorgensen SJ, Klimley AP, Muhlia-Melo AF. Scalloped hammerhead shark Sphyrna lewini, utilizes deep-water, hypoxic zone in the Gulf of California. J Fish Biol. 2009:74:1682-7.

33. Diemer KM, Mann BQ, Hussey NE. Distribution and movement of scalloped hammerhead Sphryna lewini and smooth hammerhead Sphyrna zygaena sharks along the east coast of southern Africa. Afr J Mar Sci. 2011;33:229-38.

34. Ketchum JT, Hearn A, Klimley AP, Peñaherrera C, Espinoza E, Bessudo S, Soler G, Arauz R. Inter-island movements of scalloped hammerhead sharks (Sphyrna lewini) and seasonal connectivity in a marine protected area of the eastern tropical Pacific. Mar Biol. 2014;161:939-51. https://doi. org/10.1007/s00227-014-2393-y.

35. Ketchum JT, Hearn A, Klimley AP, Peñaherrera C, Espinoza E, Bessudo S, Soler G, Arauz R. Seasonal changes in movements and habitat preferences of the scalloped hammerhead shark (Sphyrna lewini) while refuging near an oceanic island. Mar Biol. 2014;161:755-67. https://doi. org/10.1007/s00227-013-2375-5.

36. Guttridge TL, Van Zinnicq Bergmann MPM, Bolte C, Howey LA, Finger JS, Kessel ST, et al. Philopatry and regional connectivity of the Great Hammerhead Shark, Sphyrna mokarran in the U.S. and Bahamas. Front Mar Sci. 2017:4:1-15. https://doi.org/10.3389/fmars.2017.00003. 
37. Webb PW. Stability and maneuverability. Fish Physiol. 2005;23(C):281-332. https://doi.org/10.1016/s1546-5098(05)23008-x.

38. Hurt Jr HH. Aerodynamics for naval aviators. U.S. Navy. NAVAIR 00-80T-80. 1965.

39. Quattro JM, Driggers WB, Grady JM, Ulrich GF, Roberts MA. Sphyrna gilberti sp. Nov., a new hammerhead shark (Carcharhiniformes, Sphyrnidae) from the western Atlantic Ocean. Zootaxa. 2013;3702(2):159-78. https://doi. org/10.11646/zootaxa.3702.2.5.

\section{Publisher's Note}

Springer Nature remains neutral with regard to jurisdictional claims in published maps and institutional affiliations.
Ready to submit your research? Choose BMC and benefit from:

- fast, convenient online submission

- thorough peer review by experienced researchers in your field

- rapid publication on acceptance

- support for research data, including large and complex data types

- gold Open Access which fosters wider collaboration and increased citations

- maximum visibility for your research: over $100 \mathrm{M}$ website views per year

At BMC, research is always in progress.

Learn more biomedcentral.com/submissions 